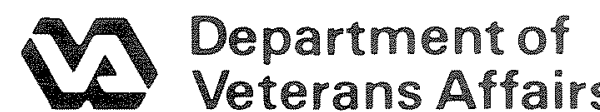

Journal of Rehabilitation Research

and Development Vol. 29 No. 1, 1992

Pages 13-18

\section{A Technical Note}

\section{A portable insole plantar pressure measurement system}

Jacqueline J. Wertsch, MD; John G. Webster, PhD; Willis J. Tompkins, PhD

Rehabilitation Medicine Service, Clement J. Zablocki Medical Center, Milwaukee, WI 53295; Medical College of Wisconsin, Milwaukee, WI 53226; Department of Electrical and Computer Engineering, University of Wisconsin, Madison, WI 53706

\begin{abstract}
To analyze plantar pressures during activities of daily living, one needs a fully portable system capable of measuring many steps over extended periods. This paper presents an inexpensive, reliable, portable plantar pressure acquisition system which we have developed. It allows the long-term recording (up to 2 hours) of pressure-time data from 14 pressure sensors within insoles. The sensor chosen is an inexpensive, conductive polymer sensor that is only $0.25 \mathrm{~mm}$ thick yet able to withstand sudden overloads. The portable, battery-powered, microprocessorbased data acquisition system has a memory space of 480 kbytes for data storage. It can collect pressure data from 14 insole sensors at a $20 \mathrm{~Hz}$ sample frequency for 5 seconds every minute over a 2-hour period. It enables the long-term measurement of plantar pressures during normal activities in a natural unrestricted environment. The design and development of this portable insole plantar pressure measurement system is described.
\end{abstract}

Key words: activities of daily living (ADL), foot, gait, insole sensors, plantar pressure, portable data acquisition system.

\section{INTRODUCTION}

There are many clinical situations where the measurement of forces exerted upon the plantar surface of the

Address all correspondence and reprint requests to: Jacqueline J. Wertsch, MD, VA Medical Center, Rehabilitation Medicine Service-117D, 5000 W. National Ave., Milwaukee, WI 53295.

This investigation was supported by the Department of Veterans Affairs Rehabilitation Research and Development Service.

Presented at the joint annual meeting of the American Academy of Physical Medicine and Rehabilitation and the American Congress of Rehabilitation Medicine, San Antonio, TX, November 9, 1989. foot is of interest. Force plate studies generally represent barefoot, isolated steps and do not allow analysis of ongoing step-to-step variations in normal walking. These measurements may not be representative of the overall daily plantar pressures. The force plate system is limited to only one step or, at most, a few steps. Coupling information from both feet during walking is not easily obtained. It is not possible to measure pressure for a large number of steps under constant conditions. Thus, analysis of ongoing stepto-step variations in normal walking may not be possible.

Placing sensors within an insole provides a method for quantitation of plantar pressures during the normal activities of a shoe-wearing subject. This technique allows pressure quantification during the normal activities of a shoe-wearing subject. Discrete pressure sensors in the insole provide localized information; therefore, the site of the sensor placement is critical. Many of the available in-shoe pressure monitoring systems have thus far remained expensive with varying signal quality; many are dependent on an umbilical connection to a remote computer for data acquisition (1-16). They typically have a limited data acquisition period (20 seconds), and thus allow recording of only a few consecutive steps. Such an early foot-toground force measuring device with an instrumented shoe was reported by Spolek and Lippert in 1976 (1). The system was restricted to measuring heel and toe forces during several steps and was not portable. Miyazaki and Iwakura in 1978 presented a portable foot-force measuring system that used two pressure transducers under each foot (2). The Electrodynogram (EDG) (Langer Biomechanics Group, New York, NY), a commercial system, employs 
Journal of Rehabilitation Research and Development Vol. 29 No. 1 Winter 1992

a microprocessor for acquiring in-shoe foot pressures from seven plantar locations $(3,4)$. The EDG can acquire data for 5 seconds from the 14 channels but has been reported to lack repeatability and accuracy, with an inherent pressure variation as great as 100-200 percent (5). An umbilical system for measuring vertical reaction forces during gait was reported by Hermens et al., in 1986 (6). The system used eight capacitive sensors which were attached to each sole. The system could store 16 kbytes of data for recording several consecutive steps during a 20 -second period. Capacitive sensors (Hercules Aerospace Division, Cumberland, MD) have been used by Patel $e t$ al., for measuring plantar pressures (17). The Hercules sensors are relatively expensive ( $\$ 150$ each), thick $(2.4 \mathrm{~mm})$, and fragile. The commercial EMED-System (NOVEL Electronics, Minneapolis, $\mathrm{MN}$ ) also uses capacitive sensors for pressure measurement and is expensive ( $\$ 6,000$ per insole). A portable strain gauge dosimeter that quantifies foot-tofloor contact forces, and stores 256 kbytes of data from 6 sensors mounted within a single shoe was described by Harris et al., in 1988 (7). Although completely portable, accurate, and reliable, the system was expensive and its use was limited to a restricted subject population. A recent commercial in-shoe pressure monitoring system, the F-Scan (Tekscan, Boston, MA) has been developed with 960 resistive sensors per insole. The insoles are usage-limited to a maximum of 50 cycles (steps) each. In addition, free unrestricted gait is not possible because the system utilizes an umbilical cable for data collection.

This paper describes an insole pressure measurement system that is reliable, cost-effective, and fully portable and allows the long-term recording (up to 2 hours) of pressure-time data from 14 pressure sensors within the insoles $(18,19,20)$.

\section{DESIGN CONCEPT}

There are several components of the system that must be considered. The foot pressure sensor must not alter the natural gait of the subject. Therefore, it must be thin and flexible so that it will not be perceived by the subject. The sensor must be durable and capable of withstanding repetitive gait cycles, yet small and thin in order to fit in the insole. It should have high sensitivity, yet be able to withstand large overloads. It should have a short response time and low power consumption. The sensor must be wearresistant, especially with friction or shear. Low hysteresis is highly desirable. Moderate nonlinearity is acceptable since the nonlinearity can be compensated for in the data processing software. The sensor should have a defined sensitivity to temperature and humidity so it can be compensated. It should be able to measure pressures in the range of 0 to 1.2 megapascals (MPa) with high stability and repeatability. The lead wire connections to the sensors should maintain electrical integrity while providing flexibility and durability.

The data acquisition system should be portable so that the gait being studied is not restricted to a small area around a host processor. The portable unit must have sufficient memory to store the complete pressure-time data at multiple sites with a high enough sampling rate to assure resolution of the complete signal. It should also have the ability to readily adjust the sampling rate required for different clinical tests. The system should be able to run for several hours without a battery change and be conveniently reprogrammed.

\section{DEVICE DESIGN}

\section{Sensor evaluation}

A large number of pressure sensors were screened (17-24). The requirement that the sensors be small and thin, in order to fit in the insole, eliminated most commercial sensors from consideration. Also, most commercial pressure sensors can withstand overloads of only 100 percent before failure due to permanent deformation. Thus, although pressures are measured in the normal range of 0-1.2 MPa, sensors are required that can withstand the occasional high pressures caused by jumping or stepping on a small object (e.g., a pebble under the shoe). With these requirements, the evaluations eliminated many commercial sensors, particularly those that use strain gauges.

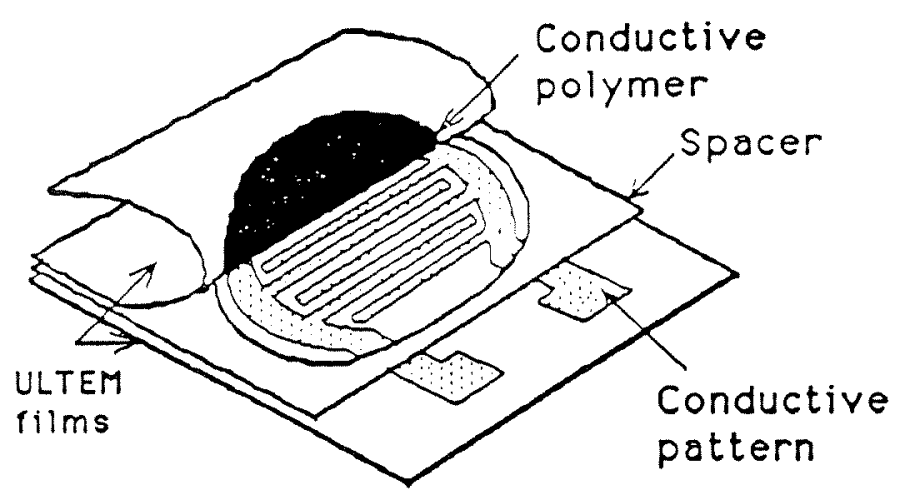

Figure 1.

Interlink pressure sensor $11 \mathrm{~mm}$ in diameter consisting of two layers: a conductive polymer film and a mylar layer impregnated with two interdigitated silver patterns. 


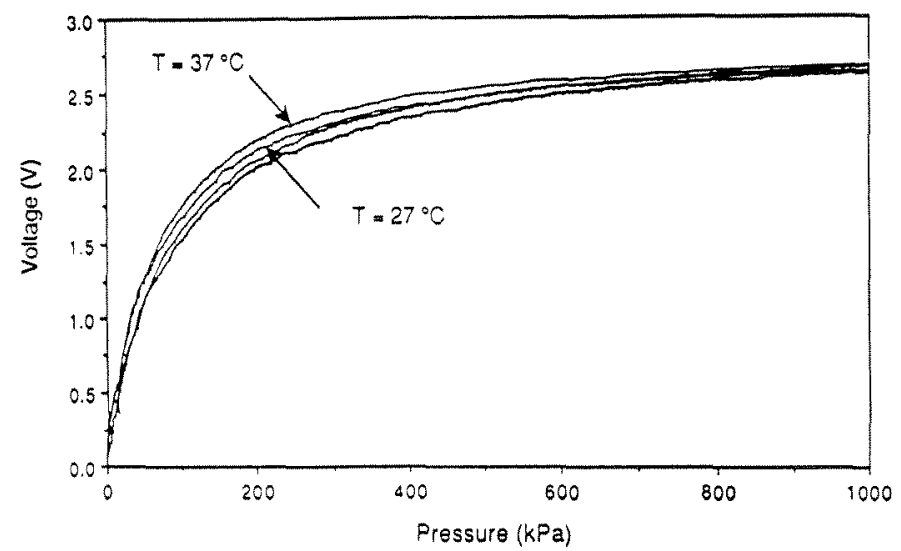

Figure 2.

Voltage-pressure response of an Interlink pressure sensor at two different temperatures. The sensor is more sensitive at low pressures and less sensitive at high pressures.

The initial sensor chosen was the Interlink $15-\mathrm{mm}$ circle conductive polymer pressure sensor (18). This sensor (Interlink Electronics, Santa Barbara, CA) consists of two layers, a conductive polymer film suspended on a mylar film, and a mylar layer impregnated with two interdigitated silver conductive patterns. Observation of the bottom layer (using an electron microscope), reveals a surface with microscopic bumps, which act as parallel resistive switches that turn on at varying pressures. When the film is pressed against the conductive pattern, more and more bumps come in contact and cause the resistance to decrease. In the absence of pressure, resistance of the sensor is typically $10 \mathrm{M} \Omega$. It is $0.25 \mathrm{~mm}$ thick, light, flexible, and costs about one dollar. The hysteresis is 8 percent and the nonrepeatability is less than 7 percent of full scale (0-1.2 MPa). The temperature drift is -0.5 percent/degrees $\mathrm{C}$ of full scale.

In May 1988, Interlink replaced the mylar construction with GE Ultem plastic, incorporated an O-ring spacer between the metal lands and the conductive polymer (Figure 1). These sensors are $11 \mathrm{~mm}$ in diameter and 0.5 $\mathrm{mm}$ in thickness. The resistance versus pressure characteristic of the sensor is logarithmic. Ten sensors were tested and it was found that the hysteresis was between 5 and 10 percent of full pressure scale of 0 to $1.2 \mathrm{MPa}$ (19). The maximal pressure nonrepeatability for increasing pressure at any data point was between 5 and 8 percent of full scale. The rise time of the sensor was determined by measuring the time between 10 percent and 90 percent of maximal output response to a hammer strike and was about 0.26 ms during the rising and falling edges of the step response.
Figure 2 shows the characteristic of an Interlink pressure sensor. The sensitivity of the sensor with amplifier is nonlinear and ranges from 0.3 to $30 \mathrm{mV} / \mathrm{kPa}$. It is more sensitive at low pressures and less sensitive at high pressures. The nonlinearity of the sensor was compensated by using a calibration lookup table. The maximal temperature related drift is -0.8 percent/degrees $\mathrm{C}$. Since the sensor is sealed, it is insensitive to humidity. Advantages of these sensors are that they can withstand large overloads, are inexpensive, and need relatively simple circuitry. Disadvantages (nonlinearity, moderate hysteresis, and moderate temperature sensitivity) were compensated by the experimental protocol and use of calibration lookup tables.

\section{Sensor placement}

To determine where to place the sensors, many available footprint techniques such as APEX foot imprinter (APEX, Hackensack, NJ), microcapsule socks, Fuji Pressensor Mat, and Shutrack system for locating sensors were investigated. The APEX foot imprinter worked best for applications in terms of accuracy, simplicity, and cost. To determine the sites of greatest weight-loading, a subject walks three times on an APEX footprint mat that has been evenly inked and covered with paper. The operator averages the locations of the highest pressure area centers, which appear dark. The operator then aligns the APEX paper on the insole to lay out the seven sensor locations (20). Figure 3 shows an instrumented insole with seven sensors and the connecting cable.

To reduce excessive hysteresis due to bending, small 1-mm thick metal backings were made for each sensor to keep them flat throughout the step cycle. The insole was hollowed out enough to accept the thickness of the metal backing, hence the resulting sensor was flush with the top surface of the insole. Subjects could not perceive the presence of the sensors in the insole while walking. Temperature distributions within the shoe were measured; there was a 30-minute stabilization period while the foot warmed up the shoe. Following the stabilization period, the temperature was nearly uniform within the shoe, at close to body temperature.

\section{Sensor calibration}

To compensate for the nonlinearity of the sensor, a sensor calibrator was constructed using a $440-\mathrm{N}$ strain gauge load cell and amplifier (21). Forces were applied through a lever system with pin joints. To prevent force measured by the load cell from being transmitted through the O-ring spacer of the Interlink sensor, an 11-mm diameter spacer was cut and taped into position so that all forces 


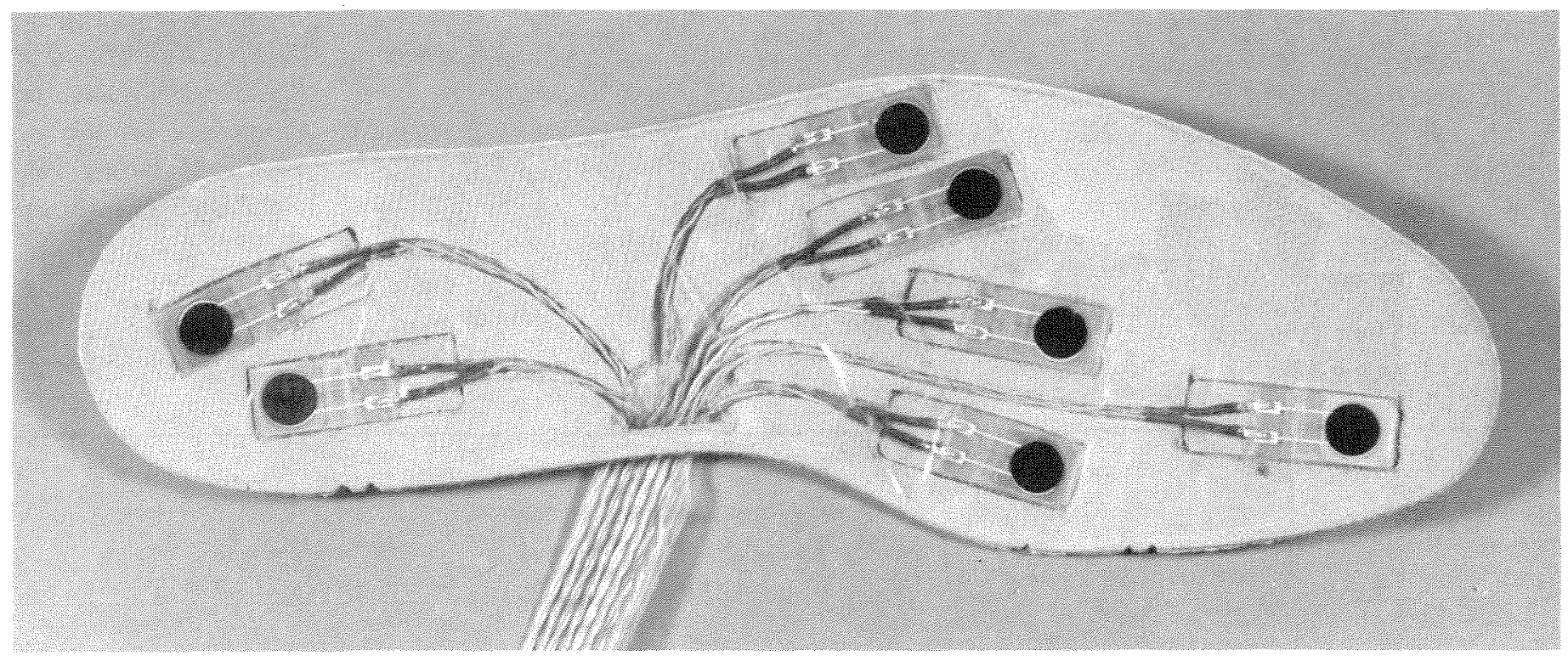

Figure 3.

An instrumented insole with seven pressure sensors located under the anterior and posterior heel, first metatarsal, second metatarsal, fourth metatarsal, fifth metatarsal, and great toe.

were transmitted through the active conductive polymer area of the sensor. Because the sensors are temperaturesensitive, an oven was constructed to surround the calibration apparatus and calibrated the insole sensors at 36 degrees $\mathrm{C}$. The IBM PC-based data acquisition system samples the outputs from the sensor and load cell and stores a piecewise linear lookup table for use in compensation for the nonlinearity of the sensor.

\section{Portable data acquisition system}

The portable microprocessor-based data acquisition system can support the long-term (up to 2 hours) recording of pressure-time data from 14 sensors. As shown in Figure 4, the system consists of 14 conductive polymer pressure sensors, 14 amplifiers (LM358), an 8-bit analog to digital converter with on-chip 16-channel multiplexer (ADC0816), a microprocessor (Hitachi HD64180), an 8-kbyte CMOS ROM (Intel 27C64), 15 32-kbyte CMOS RAMs (NEC $\mu$ PD43256), and interfacing I/O circuits (20). The insole data acquisition system is portable, batterysupplied, and book-sized. It consumes $19 \mathrm{~mW}$ at a clock frequency of $6 \mathrm{MHz}$ by providing a SLEEP mode and a SYSTEM STOP mode. The system design permits adjustment of the sample rate (by hardware switch) up to 100 samples per second to study higher frequency pressures (utilizing the same software) such as those during running or jumping activities. This system can collect pressure data from 14 channels at a $20-\mathrm{Hz}$ sample frequency for $5 \mathrm{sec}-$

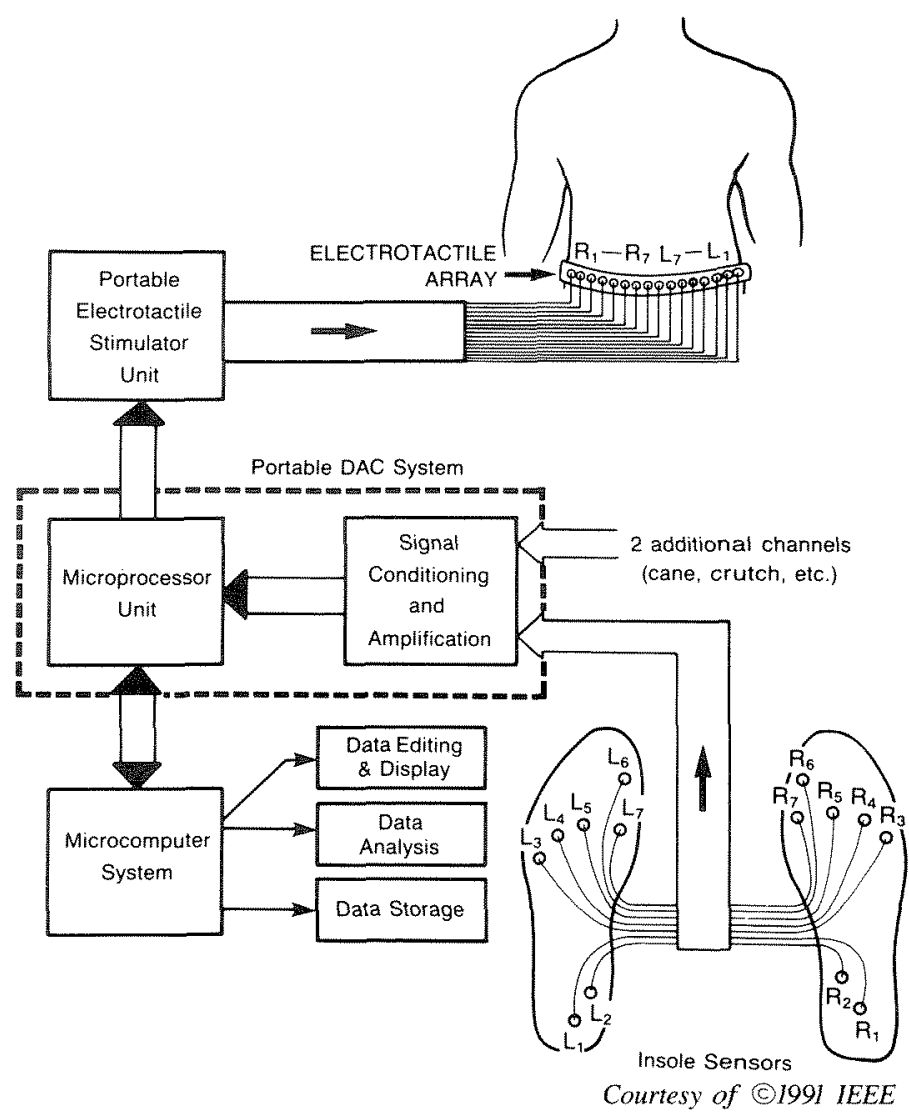

Figure 4.

Block diagram of the pressure data acquisition system, consisting of a pair of insoles instrumented with 14 pressure sensors, a portable microprocessor-based data acquisition system, and a microcomputer 


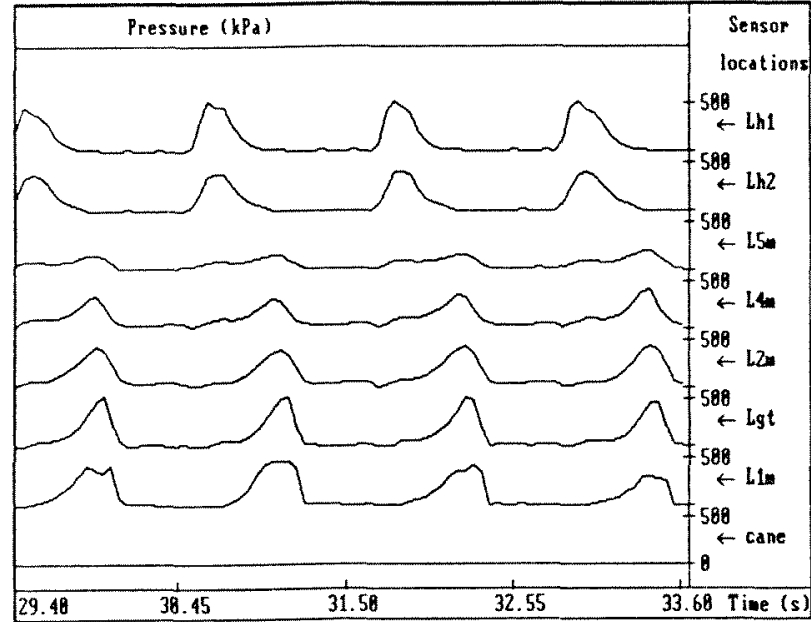

29.48

.45

31.58

32.55

33.68 Tine $(s) 29.48$

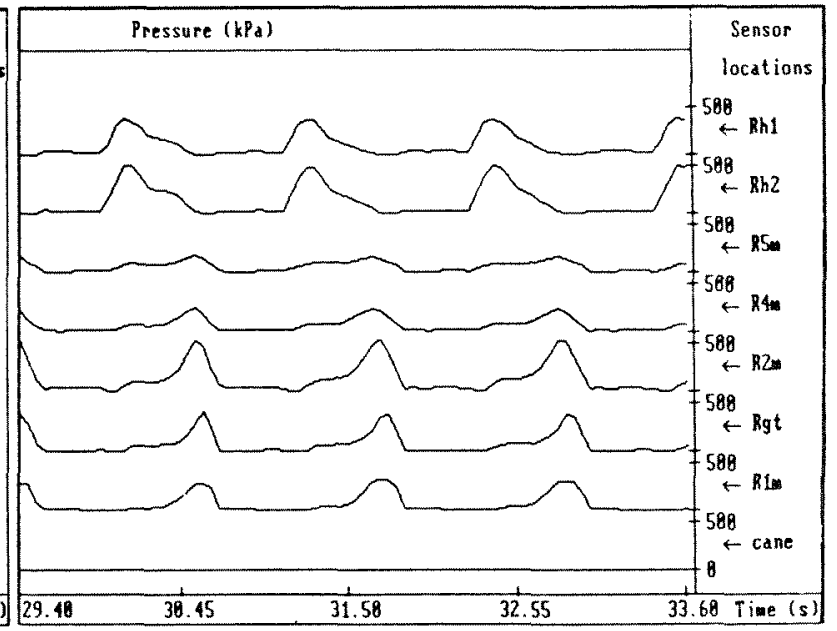

Courtesy of Archives of Physical Medicine and Rehabilitation

Figure 5.

Foot pressures during normal walking as a function of time in a typical subject. From the top to the bottom, the curves represent plantar pressures under posterior heel, anterior heel, fifth metatarsal, fourth metatarsal, second metatarsal, hallux, and first metatarsal of each foot during consecutive steps. A scale of $500 \mathrm{kPa}$ was indicated for each channel. (Reprinted, by permission, from Hongsheng Zhu, et al., Foot Pressure Distribution During Walking and Shuffling. Archives of Physical Medicine and Rehabilitation, 391, 72(6):390-397, 1991.)

onds every minute over a 2 -hour period. It can also continuously collect pressure data for 15 minutes. The data acquisition unit is $20 \times 18 \times 7 \mathrm{~cm}$ in size and weighs $0.8 \mathrm{~kg}$. Subjects carry it in a backpack during ambulation. After the test, the data are downloaded to the IBM PC, which translates the voltages into pressures by looking up prestored calibration tables. The system has the ability to run for 8 hours without a battery change and can be conveniently reprogrammed. Figure 5 shows pressure-time data of a typical subject during normal walking.

\section{CONCLUSION}

A fully portable, microprocessor-based insole pressure measurement system is described. The system can be used to collect data for up to 2 hours. It is portable and does not interfere with the natural gait pattern of the subject. It allows analysis of plantar pressure-time data during activities of daily living in an unrestricted environment. The portable system has been used for studying sensate and insensate plantar pressures, shuffling gait versus normal walking, and loading pattern during contra/ipsilateral cane

Figure 4 (Continued)

for data display, analysis, and storage. An optimal electrotactile display is available. (Reprinted, by permission, from Hongsheng Zhu, et al., A Microprocessor-Based Data-Acquisition System for Measuring Plantar Pressures from Ambulatory Subjects. IEEE Transactions on Biomedical Engineering, 713, 38(7):710-714, 1991.) use $(26,27,28)$. It has also been used to study cane cadence measurement, plantar pressures of total contact cast, and stump pressures of the below-knee prosthesis (unpublished observations). The system has been interfaced with a portable electrotactile stimulator to provide sensory feedback for the insensate foot (29).

\section{REFERENCES}

1. Spolek GA, Day EE, Lippert FG, Kirkpatrick GS. Ambulatoryforce measurement using an instrumented-shoe system. Exp Mech 1975;15:271-4.

2. Miyazaki S, Iwakura $H$. Foot-force measuring device for clinical assessment of pathological gait. Med Biol Eng Comput 1978; 16:429-36.

3. Maffei P, Power-Barnes MR. Computerized gait analysis: a quantitative diagnostic tool. Diagnosis II 1984;23-7.

4. Polchaninoff M. Gait analysis using a portable, microprocessorbased segmental foot force measuring system. In: Proceedings of the IEEE 7th Annual Symposium on Computer Applications in Medical Care, Silver Spring, MD, 1983. New York: Institute of Electrical and Electronic Engineers, Inc., 897-9.

5. Brodsky JW, Kourosh S, Mooney V. Objective evaluation and review of commercial gait analysis systems. In: Proceedings of the American Orthopedic Foot and Ankle Society, Las Vegas, NV, February 1989. Park Ridge, IL: American Orthopedic Foot and Ankle Society, 1989;24.

6. Hermens HJ, deWaal CA, Burke J, Zilvold G. A new gait analysis of system for clinical use in a rehabilitation center. Orthopedics 1986;9:1669-75

7. Harris GF, Riedel SA, Weber RC. Validation and preliminary study of the AAMRL/BBD portable force dosimeter. In: Proceedings of the 34th International Instrumentation Symposium (ISA), 
Journal of Rehabilitation Research and Development Vol. 29 No. 1 Winter 1992

Albuquerque, NM, May 1988. Triangle Park, NC: Instrument Society of America, 391-6.

8. Bauman JH, Brand PW. Measurement of pressure between foot and shoe. Lancet $1963 ; 1: 629-32$.

9. Chizeck HJ, Selwan PM, Merat FL. A foot pressure sensor for use in lower extremity neuroprosthetic development. In: Brubaker C, ed. RESNA ' 85 Proceedings of the 8th Annual Conference, Memphis, TN, June 1985. Washington, DC: RESNA PRESS, 1985:379-81.

10. Frost RB, Cass CA. A load cell and sole assembly for dynamic pointwise vertical force measurement in walking. Eng Med 1981; 10:45-50

11. Gross TS, Bunch RP. Measurement of discrete vertical in-shoe stress with piezoelectric transducers. J Biomed Eng 1988; $10: 261-5$.

12. Hennacy RA, Gunther R. A piezoelectric crystal method for measuring static and dynamic pressure distribution in the feet. J Am Podiatr Assoc 1975;65:444-9.

13. Hennig EM, Cavanagh PR, Albert HT, Macmillan NH. A piezoelectric method of measuring the vertical contact stress beneath the human foot. J Biomed Eng 1982;4:213-22.

14. Lereim P, Serek-Hanssen F. A method of recording pressure distribution under the sole of the foot. Bull Prosthet Res 1973; 20:118-25.

15. Miyazaki S, Ishida A. Capacitive transducer for continuous measurement of vertical foot force. Med Biol Eng Comput 1984; 22:309-16.

16. Soames RW, Blake CD, Scott JRR, Goodbody A, Brewerton DA. Measurement of pressure under the foot during function. Med Biol Eng Comput 1982;20:489-95.

17. Patel A, Kothari M, Webster JG, Tompkins WJ, Wertsch JJ, Bach-y-Rita P. A capacitive pressure sensor using a phase-locked loop. J Rehabil Res Dev 1989;26:55-62.

18. Maalej N, Zhu H, Webster JG, Tompkins WJ, Bach-y-Rita P, Wertsch JJ, Price MB. Pressure monitoring under insensate feet. In: Proceedings of the Annual International Conference of the IEEE Engineering in Medicine and Biology Society, Boston, MA, November 1987. New York: Institute of Electrical and Electronics Engineers, Inc., 1823-4.

19. Maalej N, Bhat S, Zhu H, Webster JG, Tompkins WJ, Bach-yRita P, Wertsch JJ. A conductive polymer pressure sensor. In: Proceedings of the Annual International Conference of the IEEE Engineering in Medicine and Biology Society, New Orleans, LA, November 1988. New York: Institute of Electrical and Electronics Engineers, Inc., 770-1.

20. Zhu H, Maalej N, Webster JG, Tompkins WJ, Bach-y-Rita P, Wertsch JJ. A microprocessor-based data acquisition system for measuring pressures between the foot and shoe. In: Proceedings of the Annual International Conference of the IEEE Engineering in Medicine and Biology Society, New Orleans, LA, November 1988. New York: Institute of Electrical and Electronics Engineers, Inc., 1599-600.

21. Zhu H, Maalej N, Webster JG, Tompkins WJ, Bach-y-Rita P, Wertsch JJ. An umbilical data acquisition system for measuring pressures between the foot and shoe. IEEE Trans Biomed Eng 1990;37:908-11.

22. Kothari M, Webster JG, Tompkins WJ, Wertsch JJ, Bach-yRita P. Capacitive sensors for measuring the pressure between the foot and shoe. In: Proceedings of the Annual International Conference of the IEEE Engineering in Medicine and Biology Society, New Orleans, LA, November 1988. New York: Institute of Electrical and Electronics Engineers, Inc., 805-6.

23. Maalej N, Webster JG, Tompkins WJ, Wertsch JJ. A conductive polymer pressure sensor array. In: Proceedings of the Annual International Conference of the IEEE Engineering in Medicine and Biology Society, Seattle, WA, November 1989. New York: Institute of Electrical and Electronics Engineers, Inc., 1116-7.

24. Webster JG, ed. Tactile sensors for robotics and medicine. New York: John Wiley \& Sons, 1988.

25. Bhat $S$, Webster JG, Tompkins WJ, Wertsch JJ. Piezoelectric sensor for foot pressure measurement. In: Proceedings of the Annual International Conference of the IEEE Engineering in Medicine and Biology Society, Seattle, WA, November 1989. New York: Institute of Electrical and Electronics Engineers, Inc., 1135-6.

26. Zhu H, Wertsch JJ, Harris GF, Price MB, Alba HM. Pressure distribution beneath sensate and insensate feet. In: Proceedings of the Annual International Conference of the IEEE Engineering in Medicine and Biology Society, Seattle, WA, November 1989. New York: Institute of Electrical and Electronics Engineers, Inc., 822-3.

27. Zhu H, Wertsch JJ, Harris GF, Loftsgaarden JD, Price MB. Foot pressure distribution during walking and shuffling. Arch Phys Med Rehabil 1991;72:390-7.

28. Wertsch JJ, Loftsgaarden JD, Harris GF, Zhu H, Harris J. Plantar pressures with contralateral versus ipsilateral cane use [Abstract]. Arch Phys Med Rehabil 1990;71:772.

29. Onesti RJ, Tompkins WJ, Webster JG, Wertsch JJ. Design of a portable electrotactile stimulator for use in sensory substitution applications. In: Proceedings of the Annual International Conference of the IEEE Engineering in Medicine and Biology Society, Seattle, WA, November 1989. New York: Institute of Electrical and Electronics Engineers, Inc., 1439-40. 